\title{
A Survey of Consequential Loss Practices in Western Europe with Emphasis on the Chemical Industry ${ }^{1}$
}

\author{
by Roy Damary ${ }^{2}$ and Peter Schmeer ${ }^{2}$
}

\section{Introduction}

In the choice of the chemical industry as the focus for this study, it is recognised that this is the industrial sector with the most problems in handling consequential losses. The chemical industry is atypical in its size, its complexity and its technology, although many of its problems are found in other industries.

Some consequential loss problems are however less severe in the chemical industries than elsewhere, e.g. market presence loss for consumer products, increased working costs for service industries.

The importance of consequential loss cannot be overstressed. $\mathrm{CL}$ is the area where pure risk exposure concerns losses which - even though on average less than material losses - can individually far exceed direct damages and can even represent a substantial fraction of company assets. Satisfactory risk management in $\mathrm{CL}$, which in most cases would involve insurance cover, should therefore be a desire of all responsible management.

For this study visits with some 50 European industrial companies have been made, mostly with chemical and pharmaceutical companies. The industrial interviews were conducted with insurance managers, members of economic departments and occasionally of top management. In addition, insurance companies, brokers, loss adjusters and CL specialists were contacted. All participants in the study had the opportunity of commenting on the draft report before finalisation.

Consequential loss insurance is at quite different points of development in the various European countries (Table 1). In the UK, Germany, Holland and Finland CL insurance in general may be considered well developed, with CL premiums reaching about $25 \%$ of fire premiums (30\% in Finland). But if the chemical industry alone is taken, then the only country where a high degree of development can be observed is the UK.

\footnotetext{
1 Undertaken by the GIRA Group, Geneva, and sponsored by the Geneva Association.
}

2 Of TECHNOMIC-GIRA CONSULTANTS S.A., Geneva. 
Table 1: Use of CL insurance among companies interviewed

\begin{tabular}{|c|c|c|c|}
\hline & \multicolumn{3}{|c|}{ CL COVER (\%) } \\
\hline & $\begin{array}{l}\text { None } \\
\text { or } \\
\text { almost } \\
\text { none }\end{array}$ & Partial & $\begin{array}{c}\text { Full } \\
\text { or } \\
\text { nearly } \\
\text { full }\end{array}$ \\
\hline France & 37.5 & 37.5 & 25 \\
\hline Germany & 53 & 20 & 27 \\
\hline Great Britain & 8 & 17 & 75 \\
\hline All others & 50 & 12.5 & 37.5 \\
\hline TOTAL & 39 & 20 & 41 \\
\hline
\end{tabular}

\section{The practice of consequential loss}

\subsection{Decision-making}

Good risk management practice involves as a first step the identification of risks and an attempt to eliminate or reduce them before they are even created.

For consequential loss, this step must begin at the investment planning stage as production units are designed and approved for investments, and continue as changes occur in production and external conditions.

Consequential losses are of two fundamental types :

- Those associated with the lost or reduced production/sales of one plant, be it from lost production capability, lost supply of raw materials or lost markets (supplier and customer extension losses). There are two simple variants of this:

- production and corresponding sales are lost and consequential loss equals the unachieved gross profit, but losses are limited to the one plant ;

- lost production may, in whole or in part, be replaced by calling on alternative, unused capacity or buying in the product from competitors. Thus sales and market position are not lost but there are increased costs of working. If the bought in product is paid for at full commercial value the $\mathrm{CL}$ is not less than the gross profit, but at least market presence is maintained.

- Consequential losses with a chain reaction where loss of a given production unit has repercussions on other steps in the production further down the chain. This is typical for the chemical industry where most products are part of a long chain. If 
the loss of production from the damaged plant cannot be made up by outside purchasing, then the worst possible situation can arise of a whole series of plant having to be closed down because of shortage of feedstock. This can happen in the chemical industry when capacity is fully used for a given product. For many products, facilities at ports, in specialised vessels or pipelines may be bottlenecks.

To reduce consequential losses of the chain type, the most careful investment plans need to be made in which a compromise has to be made between seeking concentration in production units to achieve lower unit costs and spreading production units so that the loss of any one is not too disastrous.

In making this choice, a company must consider the availability of its products on the open market. Such availability varies from time to time, but certain products are associated with an open market virtually always: petroleum products, petrochemical feedstock, for example. Chemical intermediates tend not to be so available.

\subsection{Risk analysis}

The usual situation for CL risk analysis is that the production set-up is "given " and the risk analysis involves determining the likely consequences of the loss of a given plant or plants, or of the raw material supply. (Nevertheless CL considerations can most usefully be taken into account for new plant decision.)

It should be noted that chemical companies are far from all carrying out the risk analysis described below. Many do not bother at all, and it can even be stated that no chemical company does such an analysis completely. The essential is to identify the major risks and their associated estimated maximum losses, and this is possible via an overview to identify the key risks, followed by more detailed analysis on them.

Consequential loss is deceptively simple in that within the conventional insurance framework, the key figure is the gross profit. Gross profit is almost always known for a given profit centre and therefore easily identifiable. In fact, as we argue elsewhere, gross profit is a poor measure as to actual exposure. What really counts is the loss potential and the risk spectrum (size of risk versus probability).

Every chemical company has its own flow chart representing the movement of products and intermediates through the enterprise. This flow chart can serve as the starting point for identifying the consequential loss exposure. Theoretically, an examination should be made of the likely impact of the loss of each production unit and the services such as power, steam and central controls. In practice, any chemical company is well aware of the three or four key risks which involve a consequential loss exposure of the "chain" type. These alone need to be examined in detail.

With the knowledge of alternative sourcing possibilities and likely physical restrictions on deliveries, the risk analyst now has to follow through the consequences of lost production of the unit out of action and all the other upstream and downstream units affected. He has to make assumptions on how long it would take to replace the plant and for how long buffer stocks can maintain sales. The degree of duplication of each stage of products has to be assessed. He may have to consider contamination risks and possible government intervention prolonging shutdown. The end result must be a conversion to lost turnover, which can then by the proportional rule be converted to lost gross profit. 
The loss potential (for which most insureds, rightly or wrongly, use the EML) so established is for $\mathrm{CL}$, it has little to do with material damage. A link however must be made with material damage in establishing CL loss potential in that the question has to be asked if there is serious risk of a given plant exploding and destroying neighbouring plants on the same site.

The risk analysis described above is, despite its verbal simplicity, a highly sophisticated operation involving specialist knowledge, directly associated with making a business interruption survey. It also involves calling upon personnel with more specific knowledge: production specialists, purchasing specialists, marketing specialists, and cost accountants. The risk analyst has to have access to many people and to enjoy a great deal of goodwill in bringing together the information required.

One of the most delicate steps of the whole operation is making assumptions on future capacity utilisation both of the company concerned and of the industry as a whole.

Having estimated the loss potential for the $\mathrm{CL}$, the risk analyst is acting in a position to move some way towards drawing up a risk spectrum, although he must have an inception risk analysis, i.e. one concentrating on causes.

\subsection{The role of the broker}

The responsibility for the business interruption survey or the risk analysis of consequential loss is basically that of the insurer, although it is not necessarily the insurer's personnel who undertake the survey. For many industries it is often the broker who carries out the survey and the insurer accepts the broker's analysis, but for the chemical industry, particularly in the UK, direct analysis by the insurer is more common.

Since business interruption surveys are more complicated as chemical companies get larger, it is of interest to note that brokers are used for interruption surveys mainly among the smaller firms interviewed and in greater proportion in France than elsewhere. Overall breakdown of the main source of interruption surveys (with or without insurance) were :

\begin{tabular}{lr} 
- carried out in-house & $32 \%$ \\
- broker & $28 \%$ \\
- insurer & $16 \%$ \\
- outside expert & $4 \%$ \\
- no survey & $20 \%$ \\
\cline { 2 - 2 } & $100 \%$
\end{tabular}

There may be some contradiction here between what many large brokers would claim to be able to do and what large chemical companies expect them to be able to do.

\subsection{United States practice}

The main difference between the US practice and European seems to be that there is no concept of an indemnity period in the former. Instead the gross profit is covered by the insurer until production is again started, with possible extensions of cover for 30 , 60 or 90 days. The insured may restrict the amount of coverage by co-insurance clauses. A compulsory time excess of five days is usual in interruption covers for petrochemical plants in the USA. 
Rates are less than in Europe, but this simply reflects the fact that cover is less complete. The major problem seems to be the lack of cover for reduced turnover in the months covering plant start-up (this being covered in European CL policies).

Because the US system is so oriented on production it is more justified when alternative (but higher cost) product sources are available so that sales are not lost and the interruption losses cease on start up.

\subsection{The Finnish practice}

Finland is in the unique situation of having a single insurance company offering consequential loss insurance to industry. The company, called Otso, has a virtual monopoly for industrial insurance, and accounts for over $90 \%$ of the CL premium in Finland and over $50 \%$ of the policies (most of the other $50 \%$ are small commercial enterprises and shops). Otso is owned by four leading fire insurance companies in Finland (of which two are sister companies).

Otso was created in 1939 and over the years has accumulated great experience in $\mathrm{CL}$ for Finland's traditional industries, notably those associated with paper and with timber. For such industries, the company is able to determine rather precisely the total premium required from the industry sector involved and then attempts to rank the members of that industry in order of increasing risk (assessed by inspection of the insureds' premises and observation of staff performance). It then proceeds to apply lesser ratings to those companies early in the list and greater to those later. In this way Otso covers its premium requirements and shares the premium equitably.

For industries, such as the chemical industry, where neither Otso's experience nor size of the Finnish industry can provide the same basis for premium calculation, Otso is obliged to turn to the London market for rating estimates.

For all types of industry but especially for those where the Finnish portfolio base is too low, Otso makes extensive use of reinsurance, typically drawing up reinsurance treaties with direct insurers in the United Kingdom and other leading insurance countries.

Otso is very thorough in the $\mathrm{CL}$ survey work. At least yearly each industrial risk is visited by a graduate engineer often accompanied by an economist. Together they investigate the risk from the $\mathrm{CL}$ point of view. There are eight graduate engineers working full time on $\mathrm{CL}$ and engineering insurance.

A clear bonus system is employed with premiums reduced by 0 to $30 \%$ according to the loss rates of the preceding 5 and 10 years. If the loss ratio over the previous 3 years exceeds $100 \%$ a premium increase 0 to $30 \%$ can be applied for risks with an annual premium of more than FMk 100000.

$\mathrm{CL}$ following machinery breakdown is available without material damage (but this is not so for fire), and only one loss limit is supplied in Finland by Otso, that is a large oil refinery, where the limit is a very large FMk $700000\left(2 \frac{1}{2}\right.$ times the EML).

\subsection{Industrial practice on alternative sourcing}

The possibility of sourcing from other production facilities than those damaged was frequently mentioned as a reason against the need to take $\mathrm{CL}$ insurance. Chemical companies, even though they may be competitors, help each other out in the event 
of losses. This mutual understanding has grown up over the years with no formal agreement. Transfer prices in these situations tend to be fair, because the helping company is likely to be the one needing help in the future.

This widespread understanding does not mean that help is always available, since the shortage of capacity or of physical facilities may mean that the competition cannot help no matter how much goodwill there is.

Four possibilities of sourcing can be distinguished: intermediate products, from own facilities or competitors, and finished products, again from own facilities or competitors.

Where a finished product is bought from a competitor, market presence and share are protected, although nothing is done to cover the standing charges of the lost facility.

The situation become quite different, however, if intermediate products are bought in. In the chemical industry with its strong dependency of one production unit on the other, a failure of an early unit may cause the standstill of a complete production chain. Alternative sourcing can avoid this chain effect. A good example for alternative or mutual sourcing of a raw material is the ethylene pipeline in the Ruhr district in Germany.

If lost production can be compensated by other facilities within the company, the "missing" gross profit will also be provided in the extra production of these other facilities. There is no loss of gross profit in this situation and no lost sales. There are however extra costs of working arising from the additional or overtime manpower which may have to be used in the alternative facilities. Even these costs may be absorbed if the production facilities are not very labour intensive (typically the case in the chemical industry), but transports costs may be high in using the alternative plants. is in use.

Obviously the alternative facilities can only be available if less than full capacity

No lost sales and therefore no lost profit means no indemnity, and this is the biggest single area of misunderstanding among some insureds. They see the production facility out of action and the ongoing standing and labour costs, yet they receive no $\mathrm{CL}$ indemnity.

"Increased cost of working" should cover additional expenses incurred in order to maintain position, but is not always understood. Some interviewees had experienced cases where proof of increased expenses was too difficult (perhaps there were none - but the idle labour could still be seen).

Better insurer/insured communication would assist here.

\subsection{Industries}

The petroleum industry very rarely takes $\mathrm{CL}$ cover in Western Europe, although attitudes change for the North Sea and among the nationalised companies of the oil producing countries. Refinery products are relatively simple, almost identical from one refinery to another and easily available in an open market. Furthermore, European refineries are far from operating on full capacity; thus production of one refinery could be taken over by others without problems. The "chain" of losses from break- 
down of a given plant is therefore limited, and the EML associated with any one plant small enough to be absorbed by the company.

The chemical industry, however, as a whole from petrochemicals through to speciality chemicals, is quite different. Production is more concentrated and a given company highly vertically integrated. Alternative supplies are not always easily available (or are available only at high cost), because of the market situation, product variations or even physical considerations such as port size and pipeline availability.

Thus the chemical industry is a major candidate for $\mathrm{CL}$ insurance, even though the decisions made vary from company to company and, particularly, country to country.

The pharmaceutical industry is also a candidate for $\mathrm{CL}$ insurance, not least because of great awareness of the danger of loss of market presence and the fact that pharmaceutical products, being often proprietary, are not easily purchasable from other pharmaceutical companies.

There are problems specific to stocks in the pharmaceutical industry in "shelf life" limitations, the need for cold or conditioned storage, and the seasonal or exceptional nature of demand for some drugs (e.g. influenza epidemics) with frequent government regulations of stock levels.

As in the chemical industry, however, the decisions of individual companies can go either way.

It is common practice for joint venture companies to take $\mathrm{CL}$ cover even if one or both of the parent companies generally do not.

\subsection{Future development of $C L$ as seen by insureds}

If all the insureds' wishes could be fulfilled, a strong penetration of consequential loss insurance could obviously be achieved. There are also some environmental factors which will favourably influence the future of this insurance:

- especially the pharmaceutical industry has historically kept very large stocks. These stocks helped to bridge production stops for a certain time, thus decreasing the need for CL insurance. These same stocks mean, however, large capital tie up and with the deteriorating situation of the last years the pharmaceutical industry has become increasingly aware of the costs involved and are considering reducing stocks ;

- social laws will increasingly inhibit laying off personnel because of a production interruption ;

- with more sophisticated technology the risk and especially the exposure to these risks have become greater. This increase of vulnerability of industry may reach a point where even large companies cannot carry a possible loss themselves.

All the three points mentioned above may lead to a higher future demand of consequential loss insurance. There is, however, at least one point which will diminish the need : the continuing concentration within industry. Many medium-sized companies (with few products) feel themselves too vulnerable to carry a consequential loss themselves. If they are taken over by a large group the perceived need for such insurance often declines. Their total gross profit might easily be well below the EML of the larger company. 
Paradoxically, the greater efficiency of companies after mergers may lead to greater CL potential. As single large, efficient units often take the place of duplicated plants, spare parts holding is limited, and stocks are more closely controlled, greater efficiency is created alongside greater risk.

The Netherlands deserve special mention. Legislation still allows for a tax free fund building for insurance purposes. Dutch insureds are afraid that, with continuing consolidation of the EEC, Dutch laws may be changed to make this fund building impossible. In this case the need for external $\mathrm{CL}$ insurance might rise.

\section{Issues raised by the study}

\subsection{Market capacity}

The portfolio of the chemical industry in $\mathrm{CL}$ is very narrow when compared to exposures. Figures for the UK (1976) illustrate the point : tariff market premium about $£ 5$ million, individual losses historically as large (e.g. Flixborough), individual exposures even larger (e.g. one site with an EML of $£ 30$ million, partly covered by tariff market).

Within a given country (except the very small ones) the insurance profession attempts to balance its portfolio for a given sector within the country itself. Decisions are made on a national basis, not, for example, on a European basis. They are also made in the context of direct insurance, the internationalising impact of reinsurance being largely neglected.

In Continental countries the reaction of the insurers to the problem of narrow portfolio versus large risks is to impose low limits - in early 1977 FF 250 million in France and DM 125 million in West Germany. These loss limits are considered far too low by would-be users of consequential loss insurance. Indeed, chemical companies mention this limit as the main reason for not taking $\mathrm{CL}$ cover. They see the premium based on sum to be insured but a loss limit applied for below the EML.

Some insureds are aware of the fact that insurers will occasionally grant higher limits, but in this case the increase of premiums is judged excessive.

Whether or not insureds are being entirely logical (and the above loss limits are quite high compared with, for example, net profit), insurers should recognise the very negative impact these imposed loss limits have.

A more positive approach to the narrow portfolio problem would be not to limit the exposures arbitrarily but to broaden the portfolio by giving it an international dimension. Could there not be some way for European insurers, or an even wider range of insurers, to act in a way that the direct insurance capacity in consequential loss be truly additive from country to country?

\subsection{Knowledge and expertise}

There are few topics where the opinions of the insureds and insurers differ so much as that of level of knowledge and expertise available among insurers. We received quite strong objections from insurers about some of the comments made below, but repeat them as a faithful synthesis of opinions expressed by insureds. 
The most tangible measure of expertise is the quality of the interruption survey. These surveys are fairly rare, although in the UK at least they are made (but necessarily yearly) for all risks of over $£ 2.5$ million EML (1976). The comments made by insureds about interruption surveys varied from "just adequate" to "not worth the paper they are written on ". We found many cases of the insured never having received a copy of the interruption survey known to have been carried out.

Many insureds thought the number of people able to make an interruption survey for the chemical industry in a given country a mere handful, only two or three individuals. ${ }^{3}$ These people are not necessarily of a chemical industry background, but they do have adequate knowledge of chemical flow charts and interdependencies, and add this to an assessment of financial implications and even an understanding of conditions of market supply (so that alternative sourcing can be considered and analysed).

Even if some insureds admit that an insurer or broker cannot really be expected to have experts capable of coping with the problems of modern chemical or pharmaceutical technology, there is still considerable complaint that insurers lack adequate personnel to describe consequential loss insurance and analyse risks.

Several interviewees complained that their discussion partners from the insurer were of an insufficiently high level. They admitted that insurers could not send their top managers to all their customers, but added that from a certain size up, this should still be more often the case. This complaint concerned not only the position of the discussion partner, but also his knowledge about consequential loss insurance. What some of the insureds might forget in their argumentation is that top people in the insurance company have to be managers in a general sense and not experts in a specific insurance branche. On the other hand, an insurer's "expert" is not necessarily one of the top men.

Insureds in countries where brokers are extensively used also face the problems of expertise. The average broker serving small industry does not understand consequential loss insurance and is not interested in selling it either. Even among our interviewees, who belonged to large companies, we encountered the statement that their broker was not very knowledgeable in this field. One company even mentioned that their broker had never tried to sell them a consequential loss insurance. ${ }^{4}$

One respondent (to the draft report) suggested that a per diem remuneration basis for brokers would encourage them to develop the right expertise (a theme already raised in the previous "Risk Management" study, published in the "Geneva Papers" N. 2).

One reason $\mathrm{CL}$ expertise is relatively undeveloped in many insurance companies may be that CL departments are "junior" to material damage departments. Moreover, $\mathrm{CL}$ is not an activity carried out in one place but is divided between fire $\mathrm{CL}$ and engineering $\mathrm{CL}$ and, in the UK, between "home" and "abroad". Thus insurance companies may not be encouraging the growth of expertise as well as they might, and may be dispersing what they have.

3 Here for example UK insurers would insist that $6-12$ is a more accurate assessment.

4 These criticisms cannot be applied to certain large brokers, who almost alone have developed the CL markets in some West European countries. 
The solution to building more expertise must lie primarily with individual insurance companies, ${ }^{5}$ but some inter-company moves could be made. An underwriting pool along the lines of IOI in the UK would be a possible solution, although one which attracts little enthusiasm. Another would be the creation of a joint centre of expertise with one main objective : to make satisfactory business interruption surveys and also act as claims adjusters where appropriate. Their advice in making the interruption survey would also involve risk reduction. Risk reduction must imply premium reduction as an inducement to follow the advice given by the insurer. ${ }^{6}$ Since insurers complain about the size of individual risks, any attempt to reduce the size of those individual risks appears quite logical.

There are, of course, many questions to be answered about such a possible centre of expertise. Ideally, one could imagine a West European centre with a staff of, say, 10-20, supported financially by insurers and possibly reinsurers who would be able to call upon its services. These would include information and training in $\mathrm{CL}$ gathering and analysis of statistics, providing a forum, and providing a risk analysis service for individual, particularly complicated $\mathrm{CL}$ covers. The risk analysis service could also be made available to insureds if the centre took a sufficiently independent line.

The insurers supporting such a centre of expertise would have a major marketing edge over non-participants. It may be that demonstrating the expertise and knowledge of the chemical industry may, in itself, be a sufficient mechanism to change the attitude of insureds to using $\mathrm{CL}$ insurance and to using the traditional market for their $\mathrm{CL}$ insurance.

The collaboration through the FOC ${ }^{7}$ in the UK may be the embryo for this concept if its were to be only national. The British "clubs" for CL created by brokers and insurers may also be mentioned as having already helped the UK CL market greatly in its development.

All insurers, brokers and insureds might recognise that $\mathrm{CL}$ can be sold and serviced only by specialists and that a policy of encouraging and rewarding this specialisation should be followed.

\subsection{Flow of information}

Three observations arise in the context of information flow :

- it is not common practice for reinsurers to receive business interruption reports and, even though reinsurance has traditionally been based on working in the dark but trusting the direct insurers, so far as large risks are concerned, reinsurers are asking more and more to "see" the risks (when they could make more capacity available) ;

5 Some industrial insureds stated that there were too many insurances companies involved in $\mathrm{CL}$ and that none could therefore develop the expertise necessary.

${ }^{6}$ Note may be taken of a system in France of this type : the "Abonnement Preventionconseil". This involves a contract by which the insured follows recommendations made regularly and against a fee by a company approved by the Assemblée Plenière (APSAI). There are 10 or so such advisory firms. Their reports are sent to APSAI and the fire MD \& $\mathrm{CL}$ rate is reduced by $2 \%-10 \%$ (as a function of the sector).

7 Fire Office's Committee. 
- brokers (in countries where they have a major role) may stand between the insured and the insurer so that the latter does not "see" the risk. In the UK the brokers" presence is widely agreed to help the flow of information but there is a much higher level of general criticism about their role in France;

- most large chemical companies assume themselves to be unable to prepare satisfactory business interruption reports. Yet it is only within these companies that a large part of the interruption survey expertise is available and the issue seems to be of finding someone outside the company who is able to draw upon that expertise. This may imply a chemical company being more revealing about its cost structure and material flows than it cares to be, but this openess towards the insurer is the only way to deal with this problem of information flow.

One interviewee proposed that greater mutual understanding between insurer and insured could be achieved by simulation exercices worked on together. The insurer would explain the calculative methods, formulae and figures needed, while the insured would identify problems in carrying out the exercise.

Real claims settlement would then be much smoother and better risk reduction should be achieved.

A frequent reproach was that insurers are incapable of expressing themselves in a language understandable to non-insurance specialists (the Dutch, however, were mentioned as exceptions).

To these general communication problems, specific problems have to be added where CL insurance is involved, since this subject is in itself already difficult to grasp. The specialised terminology has created a communication barrier, not so much between the insurer and the insurance managers, but between the insurance managers and the rest of the company management.

Since the items insured in $\mathrm{CL}$ are not machines, buildings or other mobile or immobile objects, but the gross profit, the terminology could certainly be matched with the accountancy practices of industrial companies. The terms "gross profit", "net profit" and "cash flow" all have different uses in industrial accountancy from those of insurance parlance.

One insurer suggests that too much emphasis has been placed on "profits", and that stress should be on maintenance of business activity.

One insurer encountered has not only recognised this problem, but drawn the consequences and formulated a policy exactly according to the terminology and the accountancy practices of one of his customers. Insureds agreed that insurers could not start rewording their policies according to their customers - administrative costs would become too high - but they felt that from a certain size of company upwards (certainly the size of company we have been discussing) this should be possible.

\subsection{Marketing}

There is very little active marketing by insurance companies of CL insurance. Where markets have been quite well developed, as in the UK, the Netherlands and Germany (as a whole, not just the chemical industry) development seems to have been basically through the brokers. It is generally considered that without the brokers the market could not have been developed to where it is or maintain the present 
position, though a historical perspective must give much credit to UK insurers for leading in the field of $\mathrm{CL}$ cover development.

For the insurance companies marketing involves partly reaching the insureds and partly encouraging the brokers to be more positive in looking for CL business.

In the case of large chemical companies, the decision not to take $\mathrm{CL}$ cover is not simply that of the insurance manager or department, the real key to CL insurance lies with the board or at least that member of the board associated with financial responsibilities. $\mathrm{He}$ is the one likely to be concerned with protecting the company's assets and cash flow.

These senior managers are very rarely contacted by insurance companies, who concentrate mainly on insurance managers (scarcely avoidable although insurance managers together with financial directors could sometimes make better discussion partners). The insurer's personnel meeting with insurance managers are often said to be insufficiently highly placed or qualified members of the insurance company staff. Insurance managers we encountered frequently complained that the "top " people in insurance companies, the ones who know their consequential loss, do not come to see them and make no attempt to "sell" them on CL. 8

The insureds' criticism found supporting evidence in one interview with a leading expert on consequential loss with an insurance company who stated, with some poetic exaggeration, that "I never leave these four walls". Yet this same man was considered one of the country's leading experts on CL.

It may be concluded firmly that contacts need to be at a senior level and by senior people.

Public relations and advertising have been somewhat used in this field and the most noticeable is in France where advertisements are made both on television and in magazines of general interest. The advertisements are of a very simple type and seem to be aimed mainly at small or middle-sized companies. Their impact on large industries such as the chemical industry may be considered quite negligible.

Another type of advertising seen, not in European journals but in a leading American one, involves double-page articles dealing with a particular topic of insurance, of which consequential loss might be one example. Advertising in such magazines aimed at senior management seems the most appropriate, although the advertisements must be much shorter and with more impact that those in the American magazine referred to.

The basic message of such advertising should be that :

- consequential losses do exist and put the profitability of the company at severe risk ;

- some insurance companies have the expertise to analyse the risks, not just as technical specialists, but also as partners to top management (" total protection ");

- it is possible to reduce exposure if the right steps are taken at the right time.

Thus the problem of marketing presents itself roughly as follows:

8 Some insurers reject this criticism and cite persistent blocking by insurance managers to attempts to contact an insured's senior management. 
- the present marketing channels through brokers should be maintained;

- in addition, contacts could be made between real experts on consequential loss, the insurance manager and his superiors in the chemical and other large industrial companies ;

- some limited institutional advertising could be carried out in top management magazines.

\subsection{The way consequential loss is rated}

There is widespread opinion among insureds that the $\mathrm{CL}$ rating system as applied to large industrial risks does not link premium to exposure in a rational way. The fact that standard ratings are derived from fire material damage ratings in many countries encourages insureds in their accusation of lack of rationality; they see wide variations in the relative $\mathrm{MD}$ and $\mathrm{CL}$ components of a given loss and therefore see no reason to associate to the two rating systems.

The insureds also fail to understand the basis on which final premiums is reached for large risks. Many insurers quite deliberately decide that too much explanation of premium mechanism would not be helpful, but insureds express the opinion that they are often relying on a long-term one-to-one relationship with their insurer and are not seeking competitive tender on each policy.

The above opinions are found far less in Germany where CL ratings are independent from the fire ratings with due consideration, however, of the kind of risk. The German rating system may be long and somewhat too elaborate but it is "transparent".

The over-emphasis (as seen by insureds) of the risk between MD and CL insurance may reflect the fact that consequential loss departments are organised as dependent as fire and engineering MD departments. Many insureds feel this structure imposes an inappropriate reference framework: fire $\mathrm{CL}$ cannot be given enough independent attention, while fire and engineering $\mathrm{CL}$ are unnecessarily separated.

Consequential loss raises two general criticisms found for most clauses of insurance, viz. that neither better management nor good past claims performance are adequately rewarded.

A comment more specific to $\mathrm{CL}$ concerns the premium for larger indemnity periods. Insureds in the chemical industry claim that one year indemnity covers the great majority of losses and that extension to two years, although advisable, does not increase exposures as much as the premium implies.

But the biggest issue raised by this study on the subject of premium is that of appropriate measurement of loss potential. Gross profit (the insured value) is, for a large plant, not a measure of exposure. Ideally exposure would be expressed as a series of loss potentials for given events associated with some measure of profitability.

It is felt not only that clearer examination of loss potentials would lead to a more rational premium (to the satisfaction of insurer and insured) but that better estimation of loss potentials would encourage better risk protection.

Loss potential unfortunately raises a problem of definition and opens an area of debate that would be inappropriately entered upon here. Most insureds believe "estimated maximum loss" (EML) to be a reasonable measure of loss potential and 
are happy to work with it. We shall therefore equate EML to loss potential although admittedly alternatives may be found.

EML is rarely brought into the open between insured and insurer. Yet it is possible that if EML were carefully established and jointly agreed upon between insured and insurer, a far better mutual understanding could be reached. Insurers would be able to adjust their premiums more rationally and the insureds would feel that they were being treated more carefully. At the same time, the very fact of having to establish a carefully explained EML would much enhance the usefulness of the business interruption survey and therefore greatly help bring about a climate in which business interruption surveys were done properly and the necessary skills duly developed.

In the UK, EML is generally not an openly discussed subject nor are there clear rules linking EML to ratings.

In France and Germany, such rules do exist (mainly as a protective device for insurers) but, again, most insureds interviewed either did not know of the rules or believed that EML did not affect rating.

The situation in Germany is that for a ratio EML/sum insured of $25 \%$, the basic rating is applied, with adjustment up or down either side of $25 \%$. At a ratio of $85 \%$ the add on is $30 \%$ to the rating, and at $5 \%$ ratio the rebate is $22.5 \%$.

This EML adjustment is over and above rating increases in Germany for all sums insured exceeding DM 50 MM.

Some German insureds reacted against the imposed responsibility (and implied sanctions) of having to estimate their EML.

A detailed reply to this chapter was received from a UK CL expert. The reply puts EML more into context than the above and emphasises the need to think in terms of classes of $\mathrm{CL}$ insurance. The reply is reprinted in the Appendix.

In any event, there appears to be a strong case for insurers to make EML or some measure of loss potential the subject of explicit analysis and linked to a risk profile.

\subsection{Type of CL cover}

There are few areas of questioning by insureds on type of cover available, viz, the dependence on material damage, R\&D, international cover and "first loss cover".

On the first question, insureds sometimes ask if $\mathrm{CL}$ cover could be made available for any cause of loss of cash flow: fire, machinery breakdown, unavailability of supplies or outlets (the conventional covers), but also loss of the personnel because of virus or food poisoning or any other cause (within reasonable limits). Insureds are simply arguing in favour of insuring against a result with the cause identified but at least on the one policy, essentially an "all risk" cover (although the term is always a little inexact).

Some insureds also request $\mathrm{CL}$ to be available without $\mathrm{MD}$ cover.

Research and development (R\&D) raises particular problems in the pharmaceutical industry. The impact on turnover of a damage to the $R \& D$ department might be very small if anything in the short range. In the long term, however, this impact could be disastrous, not because of the cost of rework, but because of delay. Interviewees 
agreed that it is extremely difficult or even impossible to judge this impact since only a few per cent of all the new products under development today will eventually reach the commercial stage. These few per cent, however, will represent an important share of turnover in a few years' time.

If the insurers could offer a workable solution ${ }^{9}$ to this problem they would have an important sales argument towards companies with major $R \& D$ activities.

Companies with international operations have difficulties obtaining a policy for consequential loss insurance on an international basis. Difficulties arise from both insurance regulations and differences in accounting practices.

Insureds like to deal with one insurer for the international cover and want the insurer to be responsible for the arrangements from country to country. A number of insurers seem unable to make these international arrangements directly between themselves. Thus, the broker has a major role to play.

Many insureds realise that insurers are not entirely free to work internationally because of national legislation. These are severe in spite of the slowly advancing consolidation of the EEC. They have the effect (as they are intended) of creating closed national markets, smaller capacity and less competition.

Despite the problems, some industrial companies manage to insure foreign subsidiaries in the latters' country and have possible indemnities paid to the parent company as well. In some cases this may involve turning regulations and insurers point out that such illegal arrangements could not be beneficial when a serious loss occurs.

One interviewee reported than an experienced broker could always succeed in finding and establishing arrangements which an insurer would only reluctantly grant directly to his insured.

There seems to be a case for insurers to make available cover on at least a European rather than an individual country basis.

Another request of some insureds is for first loss cover to be available, i.e. indemnity be available in the event of a loss on the basis of a fixed sum rather than on the usual detailed analysis of cash flow. These insureds recognise that such an approach only works if the first loss cover is deliberately less than the EML and really involves underinsurance.

Perhaps the only thing to commend the idea of first loss cover is that some insureds seek it, no matter what the traditional, perfectly sound, insurance arguments against it are.

Finally the subject of cover available should include some comment on loss of market share. There is no real answer to protecting long-term loss of market share by insurance and insureds do not expect it. But their preoccupation with maintaining market presence and share is so great that they often put far more emphasis on contingency planning, such as possible sourcing from competitors, than on insurance. This fact explains why some industrial companies look upon $\mathrm{CL}$ insurance as irrelevant to the real risk management problem they face.

${ }^{9}$ There are already partial answers to these problems : "advanced profits", for example. 


\subsection{The practical operation of CL insurance}

During the survey we collected a number of suggestions from insureds aiming at ameliorating operating procedures. Most of these concerned claims settlement.

The contrast between the nature of claims settlement for material damage and for consequential loss should be noted. In the former the claims settlement is one of assessment of value. When the consequential loss is notified, the losses themselves have hardly started. It is therefore essential for all parties to take action to minimise the loss for mutual benefit.

CL claims settlement requires an early and close working relationship between the parties and this contrasts with the more typical distant way of working that exists in respect of material damage.

A separate CL claims settlement group within insurers could therefore be imagined with loss control a major part of their responsibility. The separation from material damage would help ensure that the required difference in attitude is achieved and claims levels better controlled. This may be considered an additional argument for distinct $\mathrm{CL}$ department in insurers.

Another important area is that one concerning premium adjustment. The need for such adjustment is universally recognised, but there are problems in the case of a wrong forecast of gross profit, when the insured could easily find himself underinsured. This is because insurers in most countries offer only the possibility of reimbursing up to $50 \%$ of premiums paid in excess while not accepting underinsurance. Even in France where large risks may be underinsured up to $10 \%$ (small risks up to $20 \%$ ) insureds still considered this insufficient. In any case, no insured likes to pay excess premium and therefore lose working funds without interest.

The recent recession years with their high fluctuation of gross profits have led to increased problems. Insureds interviewed feel that it was easier some years ago to forecast the expected gross profit. One company would simply express $\mathrm{CL}$ premiums as percentage of turnover. So long as turnover showed a steady growth with more or less fixed ratios between net profit, fixed cost and variable cost, this approach worked out quite well. In difficult years, however, net profit may be hit far more than fixed costs and the gross profit will therefore fluctuate more than the fixed cost.

The company in question has since chosen to insure only fixed cost without net profit and finds it now easier to make better forecasts so far as insurance is concerned.

In constrast to the general attitude of insureds concerning premium readjustment, one insured noted that, while retroadjustment to actual gross profit was slow, his insurers were even slower in collecting extra premium due from increasing the sum insured. Delays of up to one year were reported, largely compensating the loss of interest of the retroadjustment issue.

It was frequently suggested that insurers could either introduce plus and minus margins or consider paying interest on the surplus of premiums to be paid back (and charge interest in the reverse direction).

The issue of deductibles and the due reward in terms of downward premium adjustment arises for consequential loss as it does for other types of insurance. Large 
insureds are concerned of course not with the small conventional deductibles of, for example, DM 50000 in Germany, but with deductibles of the order of, say, DM 1 million.

Nearly all companies contacted would like to obtain larger premium reduction for high deductibles. Thus, the fact that large deductibles were an exception among our interviewees does not necessarily mean that they want full coverage, but that "it is just not worth" taking high deductibles.

According to many insureds, high deductibles should help the insurers in two ways :

- in the case of a deductible expressed in form of a fixed sum and not as a percentage of the damage, the insurer would be rid of small claims involving disproportionately high administrative work;

- whatever the form of the deductible might be (time, percentage, fixed amount), the insured would be more sensitive to $\mathrm{CL}$ exposure and his performance would therefore improve, yielding lower claims ratios which in turn should allow the insurers to decrease their premiums in the long terms.

Insureds' opinion on whether a deductible should be in terms of time, money or percentage is split. The often-used time deductible which, in its first approach, is very clear and easy can give problems as to the attribution of supplementary cost.

The argument against the money deductible that it needs readjusting each year to make up for inflation does not stand up to close examination, since the sum insured has to be re-adjusted anyway. However, an insurance source informs us that brokers and insureds at renewal times resist proportional increases in deductibles as cover goes up. Deductible in terms of percentage of the sum insured offers an elegant way of dealing with inflation.

Among these practical issues, that of indemnity period needs mentioning as one giving rise to widespread confusion. There are widely differing practices on indemnity periods, they being typically as low as six months in Finland, rising to typically 12 to 18 months in other countries. The general feeling was an "admission" that they should be longer.

One area of confusion is on the treatment of stocks. An insured with a major stock observed that, after loss of his production unit, sales would not decline until his stock was used up, by which time he could even be beyond the indemnity period. The obvious answer that he needs a longer indemnity period can be countered with the observation that the existence of his stock drastically reduces the EML - is this considered in premium ?

Another confusion concerns cut-off point for claims settlement. Some insureds observed that if they had to prove lost sales throughout the whole indemnity period, they would have real difficulty as eventually changes in market conditions and efficiency would hide lost sales. It seems that the period for considering lost sales can be less than the indemnity period so that the insured can be protected against this problem. But the rules are far from clear or known and if indemnity periods are to increase, the insureds need some assurance on this issue.

Insurers can counter both arguments. There are accumulated stocks clauses to deal with the first issue and shorter cut-off points are available. But the confusion remains and could be eliminated by more explicit explanation and policy clauses. 
Finally, we would like to underline here the fact that we have tried in this report to state as accurately as possible the problems of concern to the insureds as expressed by them. The comments made may not be always completely accurate or founded, as we have noted in some specific cases. But it is worth taking them into account and discussed by the insurers in order to improve their service in this expanding but difficult risk area for the benefit of both parties.

\section{THE DEMAND FOR CL INSURANCE}

The premium level for consequential loss insurance varies as a proportion of fire material damage from company to company, as shown in the following table.

Table 2:

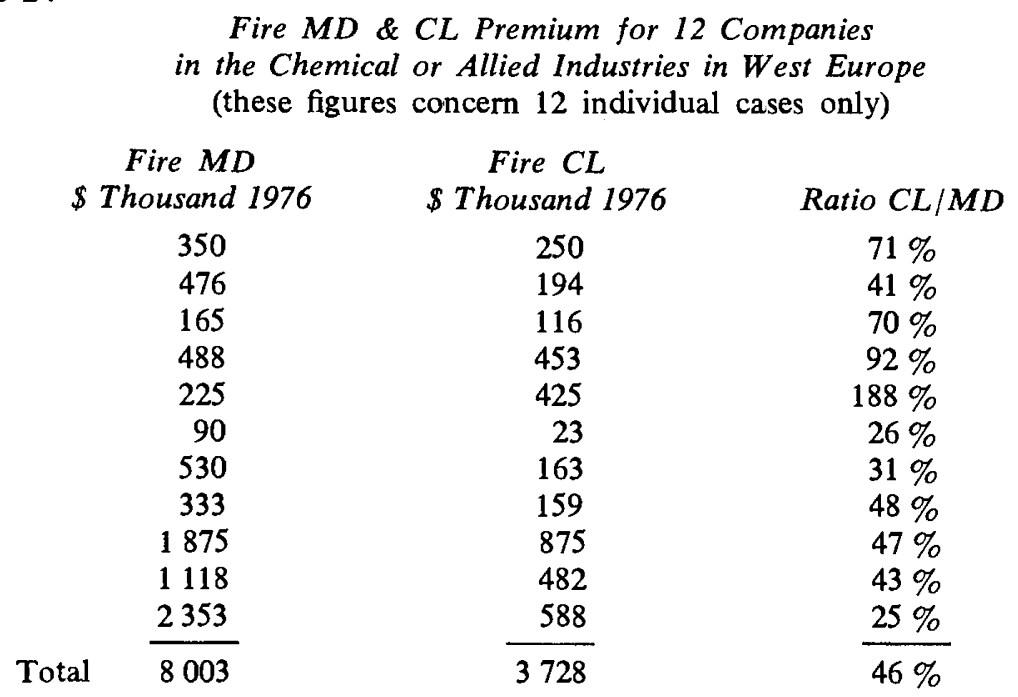

Source : GIRA

The above table does not take into account engineering $C L$ insurance, but as this is so rarely taken in the chemical industry, we could not gather meaningful relevant figures.

The $46 \%$ average ratio is, of course, valid only for users of CL insurance. If the chemical industry as a whole is taken, the proportion drops drastically because so many companies are not users. Exact figures were not obtainable for the whole sample (many respondents considered details on premium levels confidential), but we do know that $38 \%$ of the companies interviewed take CL cover. To allow for some refusals for interview on the grounds of no interest in $\mathrm{CL}$, a more appropriate ratio would be $35 \%$.

This would suggest that the ratio fire $C L$ premium: fire MD premium for the chemical industry as a whole in Western Europe is $16 \%$.

This can now be compared with estimates of the premium volume in fire MD and fire $\mathrm{CL}$ for the various countries under consideration, as in the following table. 
Table 3:

Comparison of Fire MD and CL Premium (Industry and Commerce) 1976 (these figures represent total estimate of $\mathrm{MD}$ and CL business)

(\$ Million)

\begin{tabular}{|c|c|c|c|}
\hline Country & Fire $M D$ & Fire $C L$ & Ratio $C L / M D$ \\
\hline Finland & 39 & 11 & $28 \%$ \\
\hline West Germany & 640 & 150 & $23 \%$ \\
\hline Netherlands & 167 & 35 & $22 \%$ \\
\hline United Kingdom & 680 & 128 & $19 \%$ \\
\hline Switzerland & 84 & 13 & $15 \%$ \\
\hline France & 600 & 50 & $8 \%$ \\
\hline Belgium & 179 & 14 & $8 \%$ \\
\hline Italy & 179 & 8 & $4 \%$ \\
\hline Total these countries & 2568 & 409 & $16 \%$ \\
\hline USA & 2000 & 300 & $15 \%$ \\
\hline $\begin{array}{l}\text { Factory Mutual USA } \\
\text { (losses) }\end{array}$ & 139 & 49 & $30 \%$ \\
\hline
\end{tabular}

Sources: MD - Swiss Re (also CL Switzerland).

$\mathrm{CL}$ - Mr. G. Hickmott and Gras-Savoye (for France).

Finnish figures from Otso.

Factory Mutual figures from Factory Mutual Research.

With a warning that relative $\mathrm{CL}$ and MD tariffs vary from country to country, and that conclusions cannot be based on just 1 or 2 percentage points, the following observations can be made from the above table:

- Finland has the most developed CL market relative to fire MD ;

- the UK, despite its historical lead and the relatively high penetration of CL in its chemical industry, is somewhat behind the Netherlands and Germany;

- Switzerland is in a position of medium development ;

- France, Belgium and especially Italy are underdeveloped in CL insurance relative to fire MD ;

- Factory Mutual in the USA has achieved a much higher ratio of CL/MD than has been achieved in the USA as a whole.

For the eight European countries listed, total $1976 \mathrm{CL}$ fire premium was some $\$ 409$ million.

We would suggest that further development to a ratio of $23 \%$ - that of West Germany - should be perfectly achievable. The total fire premium for the eight countries is $\$ 2568$ million, so that the premium level achievable merely by bringing up penetration to a similar level to that of West Germany would be $\$ 590$ million.

There is then the question of what is the theoretical maximum CL market if all possible users took such cover. 
We have noted the $46 \% \mathrm{CL} / \mathrm{MD}$ ratio for users in the chemical industry, compared with a ratio of only $16 \%$ for the chemical industry as a whole (reflecting the penetration of $\mathrm{CL}$ in that industry of only $35 \%$ or so of the theoretically obtainable premiums).

Such a figure cannot be extrapolated to all industries, but we would estimate that the ratio fire $\mathrm{CL}$ premiums/Fire MD premiums for users ${ }^{10}$ of $\mathrm{CL}$ (all industries) would be in the order of $30 \%$ which is roughly that of Finland today (readers are invited to generate a more accurate figure).

If the $\mathrm{CL} / \mathrm{MD}$ ratio could be increased from $16 \%$ to $30 \%$ in the 8 countries mentioned, CL premium would increase to $\$ 767$ million.

To summarise, we would estimate :

- 1976 fire CL premium volume

- volume achievable by bringing penetration to near German level

$\$ 409$ million

- volume achievable by selling CL to all potential users

of $\mathrm{CL}$ cover who already have fire MD cover

$\$ 590$ million

The figures represent a demand expansion of $44 \%$ and $88 \%$ respectively over the present situation.

These figures, as rough as they may be, illustrate the potential for development of demand for $\mathrm{CL}$ insurance in Western Europe.

\section{Appendix : The Opinion of a UK Consequential Loss Expert on the Role of EML ${ }^{11}$}

The main basic problem $I$ have is on the subject of premium, rating, deductibles and EML's in that they comprise an interrelated subject and much is a matter for the underwriter. Of course he should make it clear that risks are fairly rated one against another, but the problem lies in that this calls for a fundamental knowledge of insurance which, alas, not only insureds but insurers seem to lack.

Briefly, while total premiums per class of risk must balance, a fair individual rating plan must be applied as well (if only because rating review would otherwise be unworkable). The size of the class portfolio will govern the time cycle for balancing the overall class where the cycle is too long for practical purposes, some grouping of classes (usually of the larger exposures only which create the imbalance in a class) is necessary.

Where over-exposure of a class is excessive then international grouping, while correct in theory, is usually only of value in assessing the rate level that is technically sound. In practice, competition in individual territories from non-international insurers has to be accepted by the international insurer; otherwise he finishes up with an outof-true overall account. (For example, if he follows too low rated local markets to stay in that market, he must overcharge elsewhere to balance.) A local market with limited covers will not necessarily show up underrating except after a long period.

10 "Users" means full or nearly full cover.

11 In common with our practice elsewhere in this report, this reply has to remain anonymous, but we are most grateful to the expert concerned. 
The class rate, if based on a broad spectrum of business and a large size of premium relative to the normal loss experience and EML's is a fairly true guide to the premium level for the class as a whole. The British Tariff Companies, in fact, maintain class statistics on their business and it is from these that the class rating adjustment (CLORA) arise. The limit of circulation of these figures to only tariff members is obvious but it does lead to difficulties in not being too open to members of trade groups who seek information on rating. Nevertheless, over many years, the Committee concerned (part of the Fire Offices' Committee) has met trade groups and discussed the subject, usually with a mutual appreciation as the outcome.

The use of CLORA has largely discounted the previous, too close association of the $\mathrm{CL}$ rate to that for material damage, i.e. the fire rate. However, by leaving the limited association, it is possible to create a practical code of rating for the individual cases in the class (subject to an individual review for special individual features of these at Committee where requested). This is not too onerous administratively. Of course, while fair individual rates are to be sought, it is an axiom that there is no rate for an individual's case as such (i.e. one that will stand up on its own experience - this is why insurance is a pooling arrangement).

The problem regarding EML's is that they are a matter of opinion. Much could be done to codify this area of technology. Further, a true EML is a matter of guidance as to the maximum acceptance of a risk against an underwriter's portfolio. It is of value to insureds in assessing the exposure of their business. For rating the true information required is more complex, viz.

(a) Number of small losses

(b) Number of medium losses and their average size in money terms

(c) The incident rate of major losses and some appreciation in money terms or range that can apply.

(a) is mainly an individual case matter (and also of value in assessing the worth of a deductible), (b) is a class matter but (c) is the unknown which in the end has to be spread over (i) the class, (ii) the whole portfolio (to the extent the cases in it give this size of exposure) and (iii) over a time scale of more than one year.

Thus, EML is not a rating matter as such. The premium is a matter of the number of exposures at risk as well as their loss potential. Too often an insured thinks that the EML governs the premium. (Nine private houses each of the same value require nine times the premium of that for any one, but probably the premium for one house of nine times the value would be less than this aggregate premium as the probability of a loss of this size may be less). 